\title{
Call for Papers IEEJ Journal of Industry Applications Special Issue on "Motion Control and its Related Technologies"
}

\author{
Program Committee, Industry Applications Society \\ Technical Committee of Industrial Instrumentation and Control \\ Technical Committee of Mechatronics Control
}

IEEJ Journal of Industry Applications, which is different from Transactions on Electrical and Electronic Engineering (TEEE) and IEEJ Transactions on Industry Applications, is published from July 2012, bimonthly. In order to have the impact factor of IEEJ Journal of Industry Applications, the special issue is published periodically.

Now, we are planning a special issue on "Motion Control and its Related Technologies" in IEEJ Journal of Industry Applications published on March, 2017.

Motion control and its related technologies are one of the key-technologies for IEEJ Journal of Industry Applications, and it is much important for academic and industrial fields to discuss and clarify the trends of motion control technologies. In this special issue, we recommend to submit the extended papers of 2016 IEEJ 2nd International Workshop on Sensing, Actuation, Motion Control, and Optimization (SAMCON2016) and as well as the unpublished original papers on Motion Control and its Related Technologies.

Note that some contributed papers may be treated as general papers according to the review process.

\section{Publication schedule for the "Motion Control and its Related Technologies" Special Issue is as follows. \\ 1st, May, 2016 Deadline for submission of papers to the Special Issue \\ March, 2017 Publication of the Special Issue \\ Website $\bullet$ https://submit.iee.or.jp/main/cgi/sstk-top.cgi}

IEEJ publishes several types of Transactions. Thus, please make sure to select IEEJ Journal of Industry

Applications (English only) from the drop-down list of choices when submitting your paper. In addition, please choose the special issue theme entitled "Journal IA 2017/3(E) Special Issue on Motion Control and its Related

Technologies" from the drop-down list at the paper submission screen.

\section{IMPORTANT NOTICE}

1) The submitted papers will be reviewed based on the Author's Guidelines for IEEJ.

URL http://www.iee.jp/wp-content/uploads/honbu/32-doc-kenq/guideline.pdf

2) Note that the manuscript will not be included in the Special Issues, if the manuscript is not accepted for publication by the deadline for the Special Issue as a consequence of revisions requested by referees.

3) The authors (or their institution) are requested to pay publication charge. See for details in the Author's Guidelines.

4) Papers should be submitted on the web-based system. For online submission, authors are requested to register as a user.

\section{CONTACT}

Guest Editor, Special Issue on Motion Control and its Related Technologies:

Prof. Makoto IWASAKI, Nagoya Institute of Technology (E-mail: iwasaki(at)nitech.ac.jp)

Prof. Hiroshi FUJIMOTO, University of Tokyo (E-mail: fujimoto(at)k.u-tokyo.ac.jp) 